\title{
ABORDAGEM HISTÓRICA DE UMA MATA DESTINADA A CONSERVAÇÃO AMBIENTAL NO MUNICÍPIO DE DOURADOS-MS
}

\author{
(HISTORICAL APPROACH OF A SMALL FOREST UTILIZED FOR ENVIRONMENTAL CONSERVATION IN \\ DOURADOS MUNICIPALITY, MS)
}

\author{
Cláudia Regina Bosa ${ }^{1}$, José Aderlan² \\ ${ }^{1}$ Doutoranda em Parasitologia/UFPR; Mestre em Zoologia/UFPR; Professora do Curso de Pós \\ Graduação em Conservação da Natureza e Educação Ambiental - PUC/PR \\ 2 Especialista em Conservação da Natureza e Educação Ambiental- PUC/PR.
}

crbosa@hotmail.com, aderlanj@hotmail.com

\begin{abstract}
RESUMO
A Educação Ambiental é fundamental no processo de conscientização dos seres humanos sobre a necessidade de mudança de hábitos, tanto individuais como coletivos, e na busca de soluções para amenizar os problemas ambientais. Este estudo, realizado no Centro Educacional e Social Marista (CESMAR), localizado na Comunidade João Paulo II, na cidade de Dourados no Estado do Mato Grosso do Sul, buscou diagnosticar a percepção em relação aos aspectos culturais e de consciência ecológica. Através do resgate da memória histórica da comunidade local, analisou-se a contribuição dos Irmãos Maristas para a proteção da mata na área pesquisada. A partir da abordagem quanti-qualitativa com entrevista semi-estruturada e questionários, envolvendo pessoas da comunidade e educandos do CESMAR, analisamos os problemas identificados na área estudada.
\end{abstract}

Palavras-chave: Educação Ambiental; CESMAR; Conservação da natureza.

\begin{abstract}
The Environmental Education is essential in the process of human consciousness in relation to the need of individual or group habits changing, and in the searching of solutions to decrease environmental problems. This study was performed on Marist Social and Educational Center (CESMAR), located in João Paulo II Community, in the city of Dourados, Mato Grosso do Sul state. This study aims the description of the cultural aspects and ecological conscience perception. The contribution of the Marist's Brothers to the protection of the forest on the researched area was evaluated through the search of the local community historical memory. We analyzed the problems of the studied area by the use of quantitative-qualitative approach with semi-structured interviews and questionnaires, involving people from community and students from CESMAR.
\end{abstract}

Keywords: Environmental Education; CESMAR; nature conservation. 


\section{INTRODUÇÃO}

Atualmente são bastante visíveis as conseqüências do aquecimento global. Segundo a C.D.B.(Convenção sobre a diversidade biológica) 2005. O desmatamento e a fragmentação de habitats são as principais ameaças à perda da biodiversidade. Essa constatação exige a ampliação do olhar para o objetivo da Educação Ambiental, procurando compreender sua contribuição para o desenvolvimento da consciência ecológica na atualidade.

Patrick Geddes, considerado "pai" da educação ambiental, expressou sua preocupação com os efeitos da Revolução Industrial, iniciada em 1779, na Inglaterra, pelo desencadeamento do processo de urbanização e suas conseqüências para o ambiente natural (DIAS, 2002).

Pode-se afirmar que os olhares para a questão ambiental começaram a tomar novo rumo, em nível internacional, ao longo das duas últimas décadas, com base em uma série de eventos, como as Conferências das Nações Unidas sobre o Meio Ambiente em Estocolmo (1972) e a Conferência Intergovernamental das Nações sobre Educação Ambiental Tbilisi (1977), que originaram as primeiras manifestações de redefinição da Educação Ambiental.

A primeira definição internacional da Educação Ambiental foi adotada pela International Union for the Conservation of Nature (IUCN, 1971), que enfatizou os aspectos ecológicos da conservação. A Conferência Intergovernamental de Tbilisi (1977), internacionalmente mais aceita, definiu que: a Educação Ambiental é um processo de reconhecimento de valores e classificação de conceitos, objetivando o desenvolvimento das habilidades e modificando as atitudes em relação ao meio, para entender e apreciar as inter-relações dos seres humanos, suas culturas e seus meios biofísicos. A Educação Ambiental também está relacionada com a prática das tomadas de decisões e a ética que conduzem para a melhoria da qualidade de vida (SATO, 2004).

Segundo GONÇALVES (1990), a Educação Ambiental não deve ser entendida como um tipo especial de educação. "Trata-se de um processo longo e continuo de aprendizagem de uma filosofia de trabalho participativo em que todos, família, escola e comunidade, devem estar envolvidos". O processo de aprendizagem de que trata a Educação Ambiental não pode ficar restrito exclusivamente à transmissão de conhecimentos, à herança cultural do povo, às gerações mais novas ou à simples preocupação com a formulação integral do educando, inserido em seu contexto social. Deve ser um processo de aprendizagem centrado no educando; gradativo, contínuo e respeitador de sua cultura e de sua comunidade. Deve ser um processo crítico, criativo e político, com a preocupação na transmissão e apropriação dos conhecimentos, a partir da discussão e avaliação crítica dos problemas comunitários e também da avaliação feita de sua realidade individual e social, na comunidade em que vive.

“A Educação Ambiental é um processo permanente onde os indivíduos e as comunidades tomam consciência do seu meio ambiente e adquirem conhecimentos, habilidades, experiências, valores e a determinação que os tornam capazes de agir, individual ou coletivamente, na busca de soluções para os problemas ambientais, presentes e futuros". (UNESCO, 1987).

A Conferência das Nações Unidas sobre o Meio Ambiente e Desenvolvimento, realizada no Rio de Janeiro em 1992, lançou desafios fundamentais para as políticas das Nações contidas na proposta denominada Agenda 21, destacando mais uma vez, a importância e a necessidade da Educação Ambiental na busca de um desenvolvimento sustentável (VASCONCELLOS, 2006).

Proteger a biodiversidade de um país é um compromisso de todos os segmentos da sociedade, segundo o Capítulo VI, artigo 225, da Constituição Federal de 1988. Todos têm direito 


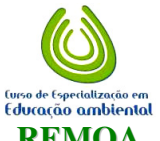

\section{Monografias Ambientais}

(Revista Eletrônica do PPGEAmb-CCR/UFSM) ISSN:

ao meio ambiente ecologicamente equilibrado, bem de uso comum do povo e essencial à qualidade de vida, impondo-se ao poder público e à coletividade o dever de defendê-lo e preservá-lo para as presentes e futuras gerações. Além da Constituição Federal, o Governo Federal decretou a Lei 9795/99, afirmando que a Educação Ambiental deve ser implementada em todos os níveis e idades.

Em 1997, na cidade de Kyoto, no Japão, foi assinado um novo componente da Convenção Marco sobre Mudanças Climáticas: o Protocolo de Kyoto. O objetivo do protocolo é comprometer as nações industrializadas a reduzir, no período de 2008 a 2012, as emissões de componentes que interferem no clima da Terra em 5,2\% em relação aos índices de emissões de 1990 (MMA, 2007).

Nesse sentido, o grupo CESMAR busca vencer desafios em Educação Ambiental, como: aliar a educação dos afetos, formando pessoas amorosas e sensíveis para com a natureza, facilitando a educação para a cidadania e formando sujeitos atentos para os problemas socioambientais, capazes de interferir nas decisões da sociedade.

\section{O CENTRO SOCIAL MARISTA - CESMAR}

Os Irmãos Maristas chegaram à cidade de Dourados em 1967, provenientes do Rio Grande do Sul. A princípio não havia interesse em construir escolas ou centros sociais. No final da década de 1960, adquiriram a área mencionada no presente estudo.

O Centro Educacional e Social Marista (CESMAR) está situado na periferia de DouradosMS, com grande demanda de serviços e programas oferecidos, principalmente em razão do perfil socioeconômico das famílias que residem no território de abrangência (ABEC, 2007).

Historicamente, a comunidade tem forte vínculo afetivo com está área destinada à conservação ambiental. Há quase dois anos a mata foi fechada para visitação pública devido à reforma e à ampliação do prédio do CESMAR. Apesar da inauguração do novo estabelecimento em 2007, a mata permaneceu fechada para visitação, aguardando possíveis alternativas para reabertura ao público, de maneira adequada, com projetos de Educação Ambiental que atendam à demanda da comunidade local e dos visitantes.

A utilização de Parques pela população local deve ser o enfoque central de qualquer planejamento de manejo, tanto nos países ricos, como nos pobres (RICHARD B., EFRAIM RODRIGUES, 2001). Diante desse contexto, o presente trabalho buscou diagnosticar a realidade da comunidade João Paulo II nos aspectos culturais e de consciência ecológica, resgatando a memória histórica da comunidade local em relação à mata destinada à conservação ambiental. Também analisou a contribuição dos Irmãos Maristas para a proteção da área pesquisada, buscando contribuir para futuras ações de Educação Ambiental na referida unidade.

Visto que de acordo com a filosofia marista, há uma busca intensa pela análise da realidade para identificar as necessidades reais e, a partir daí, propor soluções para transformar a realidade de crianças e jovens em situação de risco. 


\section{METODOLOGIA}

O estudo foi realizado na Comunidade João Paulo II, na cidade de Dourados, localizada no sul do Estado de Mato Grosso do Sul, na região Centro-Oeste. A população é de 181.869 mil habitantes (IBGE/2007). O clima da região é seco, no inverno e tropical úmido no verão. Tem clima de altitude, de verões brandos. (Prefeitura de Dourados, 2007).

A vegetação predominante na área em estudo é de floresta estacional semidecidual submontana de freqüente ocorrência nesta região. O conceito ecológico deste tipo de vegetação está condicionado pela dupla estacionalidade climática: uma tropical, com época de intensas chuvas de verão seguidas por estiagens acentuadas; e outra subtropical, sem período seco, mas com seca fisiológica provocada pelo intenso frio de inverno, com temperaturas médias inferiores a $15^{\circ} \mathrm{C}$. Esta formação ocorre freqüentemente nas encostas interioranas das Serras da Mantiqueira e dos Órgãos, nos planaltos centrais capeados pelos arenitos Botucatu, Bauru e Caiuá dos períodos geológicos, Jurássico e Cretáceo. Distribui-se desde o Espírito Santo e sul da Bahia até o Rio de Janeiro, Minas Gerais, São Paulo, sudoeste do Paraná e sul do Mato Grosso do Sul (VELOSO, 1992). O Centro Educacional e Social Marista CESMAR possui em sua propriedade uma mata natural de aproximadamente 1,20 hectares, que abriga uma pequena população de macacos prego.

De acordo com os objetivos propostos para esta pesquisa, a amostragem caracterizou-se da seguinte maneira:

Foram entrevistadas pessoas da comunidade João Paulo II e entorno, levando em conta dois públicos a saber:

10: Pessoas nascidas antes de 1980 . No que se refere às pessoas nascidas antes da década de 1980, realizou-se uma entrevista semi-estruturada, gravada, utilizando o método de grupo focal.

"A técnica de grupo focal permite a identificação e o levantamento de opiniões que refletem o grupo em um tempo relativamente curto, otimizado pela reunião de vários participantes e pelo confronto de idéias que se estabelecem, assim como pela concordância em torno de uma mesma opinião, o que permite conhecer o que o grupo pensa. Em alguns poucos encontros, é possível conhecer percepções, expectativas, representações sociais, conceitos do grupo." (CARLINI-COTRIN, 1996).

Trabalhou-se com sete (07) pessoas da comunidade, sendo moradores mais antigos da comunidade e migrantes. De início, participariam do grupo doze (12) pessoas, conforme orientação da técnica do CESMAR. MINAYO (1996) defende a importância de reuniões com um número pequeno de informantes de seis (06) a doze (12) pessoas. Neste caso, ocorreu ausência de algumas pessoas da área de saúde, pois são profissionais que não moram no território de abrangência e só vêm à comunidade para trabalhar.

Efetuou-se a reunião no dia 24 de maio de 2008 no CESMAR Dourados. Foi apresentada ao grupo a proposta da pesquisa e solicitada permissão para entrevista. Além dos usuários participantes, esta técnica exigiu a presença de um mediador, no caso o pesquisador, a quem coube o papel de explicar ao grupo quais assuntos seriam tratados. $O$ papel do mediador também é promover a participação de todos, evitando a dispersão dos objetivos da discussão e a 
monopolização de alguns participantes sobre outros. Também foi necessária a presença de um assistente, para operar o gravador.

Iniciou-se o encontro com algumas fotografias antigas do local pesquisado como recurso de registro para auxiliar a busca da memória do grupo e contextualizar as entrevistas. Foi dado prosseguimento ao trabalho com base no roteiro de entrevista em bloco. O encontro durou cerca de duas horas.

Nessa perspectiva e de acordo com ALBERTI (1990).

[...] a história oral é método de pesquisa que privilegia a realização de entrevistas com pessoas que participarem de, ou testemunham, acontecimentos, conjunturas, visões de mundo, como forma de se aproximar do objeto de estudo.

O processo de análise de conteúdo ocorreu em três fases:

a) Transcrição do material gravado: nesta etapa, realizou-se a transcrição do material gravado, atentando para a importância de se preservar a originalidade dos dados e sua legitimidade.

b) A exploração do material: na qual realizou-se a decodificação do material transcrito, organizando-o de acordo com os blocos de perguntas e sessões do grupo.

c) Análise categorial: por fim, realizou-se o desmembramento do material em categorias, para descobrir os núcleos de sentido que compunham as falas transcritas.

Com os adolescentes nascidos na década de 1990 e que freqüentam o CESMAR Dourados, realizou-se a aplicação de questionários no primeiro semestre de 2008, com 22 educandos, escolhidos a partir das oito oficinas sócio-educativas desenvolvidas no CESMAR. Foram escolhidos quatro educandos por oficina (independentemente de sexo), indicados pelo educador responsável.

Deviam participar da entrevista 25 educandos, porém três adolescentes não compareceram no dia estipulado para responder ao questionário.

Foi realizada uma reunião no CESMAR para a apresentação ao grupo, acompanhado de pais ou responsáveis, a proposta da pesquisa. Neste momento, solicitou-se, aos pais, a permissão para que o educando respondesse ao questionário conforme orientação do termo de consentimento livre esclarecido. Após explicações, foram colhidas as assinaturas.

No dia da aplicação do questionário, os educandos selecionados foram levados a uma sala do CESMAR e convidados a responder ao questionário. O entrevistador (a) preencheu os campos do questionário na presença do entrevistado, à medida que este foi respondendo. Esse trabalho evitou campos em branco no questionário.

Para compor a amostra da pesquisa, os entrevistados tiveram que atender aos seguintes critérios de inclusão e exclusão:

Critérios de inclusão

a) Crianças e adolescentes nascidos na década de 1990 insertos no Serviço de Apoio Sócioeducativo do Centro Educacional e Social Marista - CESMAR, cujos pais ou tutores aceitassem assinar o termo de consentimento livre e esclarecido. 
b) Homens e mulheres nascidos antes de 1980 moradores no território de abrangência ${ }^{1}$ do CESMAR e que com ele tenham vínculo.

Critérios de exclusão

a) Manifestação por parte do sujeito, em qualquer momento, da intenção de não mais participar do estudo.

b) Preenchimento ou resposta dos questionários de modo duvidoso ou que não pudesse ser entendido pelos investigadores.

c) Falecimento do participante durante a pesquisa.

\section{RESULTADOS}

Os dados colhidos com o uso da metodologia de grupo focal são de natureza qualitativa (MINAYO, 1996). Neste sentido esta análise também foi realizada desta forma. Não houve tratamento de dados estatísticos, mas um conjunto de procedimentos que visam organizar os dados de modo que eles revelassem com a máxima objetividade e isenção possível, como o grupo em questão percebe e se relaciona com o foco do estudo abordado. Utilizou-se como contribuição de fonte primária um relato escrito por um antigo morador:

A região do bairro João Paulo II era uma fazenda. Existia nela uma mata rica e densa. 0 bosque atual fazia parte dela. Ao redor tudo foi desmatado. Nós lutamos para preservar esta parte, pois pelo plano deviam passar pelo nosso bosque duas ruas. Viviam no mato: porco espinho, gambás, tartarugas, com mais de $20 \mathrm{~kg}$ e outros bichos. Muitos pássaros. Os macacos eram migrantes, aproveitavam o mato dos dois lados e por vezes sumiam. Felizmente, quando abateram as árvores, uns vinte macacos estavam em nossa propriedade. Não cortamos árvores. [...] J-1.

Os trechos das entrevistas citadas a seguir ilustram a realidade e a relação dos entrevistados com a área de estudo:

Tinha realmente muito bicho, eu cansei de ver ali cotia a gente olhava os macacos saiam andando. Muito bicho mesmo, cobra sem dúvida que na minha casa apareceu foi muita. Na época, uma até pegou o meu nenezinho que hoje tem 26 anos e deu um bote certinho na mão, carcou o dente".(C-1)

[...] a atração sempre foram os macacos e para nós até um incômodo o tanto de macacos que tinha destelhavam as casas e entravam nas dispensas se nós deixava a porta aberta esses encontros que tinha aqui e tinha lanche realmente não podia descuidar tinha que ficar alguém perto da mesa porque levavam muitas vezes tinha macaquinho com sacola de banana [...] B-3

[...] quando meu filho mudou pra cá tem três anos que ele mudou pra cá. Então era um ataque de macaco assim que dava raiva sabe dava raiva. Destruía 6, 7 telhas assim de uma pancada para catar. Ele teve que por cerca elétrica para parar de incomodar [...] C-1.

\footnotetext{
${ }^{1}$ Compõe o território de abrangência do CESMAR os bairros João Paulo II, Parque das Nações I e II, Vila Industrial, Jardim Márcia, Jardim Pantanal, Jardim Guanabara, Vila Vieira, Vila Ubiratan, Vila Maracanã, Jardim Santa Brígida, Jardim Cuiabá, Jardim Brasília, Jardim Canaã I, Residencial Ponte Branca e Jardim São Cristóvão. (ABEC CESMAR 2007).
} 
Com o passar dos anos, a cidade de Dourados foi crescendo e houve o aumento da devastação da mata nativa. A presença dos Irmãos Maristas foi importante para o processo de conservação da mata, conforme evidencia o relato abaixo:

Eu acho que se não fosse os Irmãos Maristas não existia mais este mato. A gente vê em outras áreas ai Dourados está crescendo, está se esparramando demais e se os irmãos não tivesse comprado isso aqui já era [...] B-1.

No relato abaixo, percebe-se que, em um dado momento, as autoridades políticas quiseram apoderar-se da área em questão para bem do poder público.

[...] um belo dia chega o senhor prefeito de Dourados dizendo que estava disposto a desapropriar nosso terreno, pois os netos iriam protestar contra as autoridades que não haviam preservado algum bosque para lazer, perto da cidade. Nossa resposta foi: Senhor prefeito, realmente as autoridades não souberam preservar mata nativa. Nós lutamos para manter dois hectares, lutaremos para preservar o bosque. Portanto, esqueça a idéia a idéia de desapropriação. [...] J-1.

Com relação à importância da mata e dos macacos para a comunidade o grupo demonstrou preocupação.

Precisamos da mata, do verde para respirarmos. Eu tenho um netinho que mora lá em cima no fundo da Aratan quando a avó desce para cá ele sente a diferença do ar que lá pra cima. Então eu vejo que jamais deve ser tirado ou mexido alguma coisa daqui, o animal precisa só do alimento ele pode ter o tanto que for que ele não vai incomodar ninguém." (C-1)

Através desta mata temos um oxigênio melhor aqui você já pensou se tira essa mata daqui? Tem que plantar mais. (B-1)

Percebe-se que o grande problema da comunidade hoje é como conviver de maneira tranqüila com os macacos.

[...] isso aqui é muito importante porque o que a gente tem que fazer cada dia melhorar mais e cuidar destes animais de que jeito. Porque estes animais sai mexendo nas casas porque falta alimento entendeu? Porque lá no mato eles tem de tudo. Lá eles tem banana de macaco, eles tem laranja verde e um monte de coisas não estão em quatro paredes e aqui não tem. Como que eles vão fazer? Eles vão ter que atacar você com fome faz coisa se você não achar quem... E o animal luta não quer saber o raciocínio dele é diferente. Então eu acho que nós mesmo tinha que cuidar melhor o alimento adequado para eles não sair atacando as casa [...] B-1.

Do meu ponto de vista é assim quanto à comunidade dos macacos eu acho que deve ser controlado porque realmente, se você deixa vai reproduzindo, reproduzindo e não tem alimento suficiente para todos. Eu acho que devem ser plantadas novas árvores que tem semente de coisa que ai eles se alimenta. E uma coisa que eu acho que precisa também é controlar o tipo de alimento que as pessoas dão quando vem. Porque acaba deixando os macacos preguiçosos por isso que eles vão nas casas é melhor ir lá ganhar do que procurar alimento então talvez seria uma forma de não deixar dar salgadinho. $O$ alimento deles é da natureza eles só vão nas casas porque foram convidados se agente não tivesse dado esse tipo de alimento eles não sabe que tinha.(C-4)

Com relação ao público nascido a partir de 1990, o questionário elaborado foi composto por 05 perguntas, com blocos de 01 a 08. A primeira pergunta, com bloco de 1 a 6 , teve a finalidade de identificar os sujeitos entrevistados. As perguntas do bloco 2 buscaram caracterizar alguns dados culturais. O bloco 3 procurou saber qual o nível de informação dos sujeitos em relação ao CESMAR e aos Irmãos Maristas. O bloco 4 procurou identificar qual o grau de 
informação que os entrevistados tinham sobre a questão ambiental levando em conta o desenvolvimento de projetos futuros.

Após aplicação do questionário, foi realizado um mapeamento de todos os dados obtidos no trabalho de campo, procurando identificar dimensões, categorias, padrões e relações. A análise dos dados foi simplificada, além de permitir a construção de gráficos demonstrativos.

As figuras 1, 2 e 3 apresentam algumas características específicas dos adolescentes entrevistados. A maioria nasceu em Dourados, cursa o Ensino Fundamental e mora na comunidade há mais de dez anos.
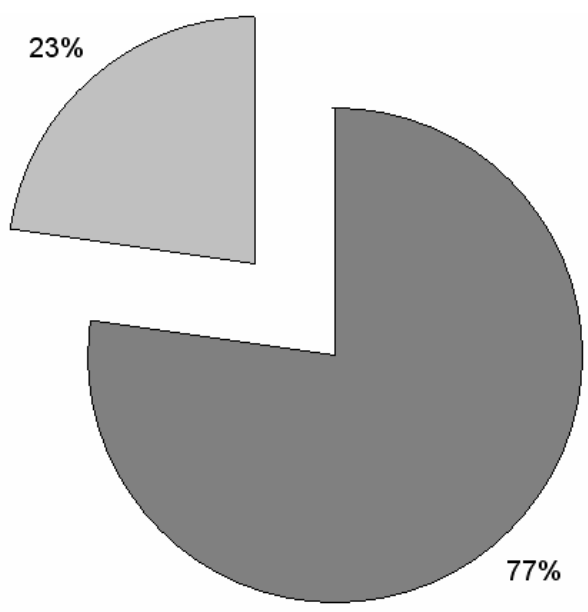

$\square$ Nascidos em Dourados $\square$ Nascidos em outras cidades

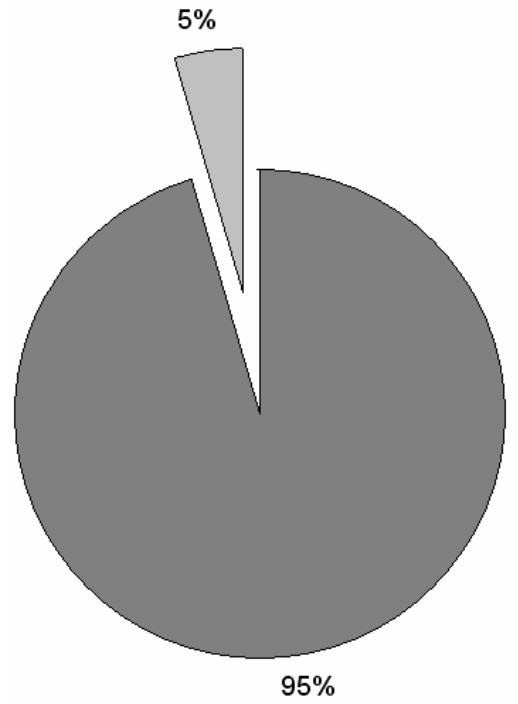

$\square$ Cursando o Ensino Fundamental II $\square$ Cursando o Ensino Médio

Figura 1 - Local de nascimento dos entrevistados. Figura 2 - Escolaridade dos entrevistados. 


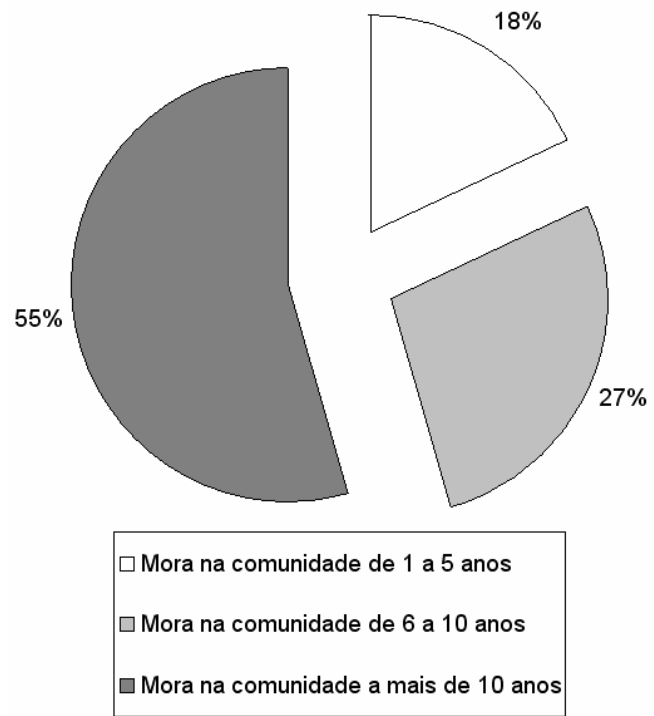

Figura 3 - Tempo de moradia na comunidade.

As figuras 4, 5 mostram dados referentes à questão cultural dos entrevistados. "A cultura é constituída pelo conjunto dos saberes, fazeres, regras, normas, proibições, estratégias, crenças, idéias, valores, mitos, que são transmitidos de geração em geração, se reproduz em cada indivíduo, controla a existência da sociedade e mantém a complexidade psicológica" (MORIN, 2002).

No processo de Educação Ambiental, há necessidade de conhecer, respeitar e utilizar a história e culturas locais. Na figura 4, percebe-se que dos adolescentes entrevistados, 59\% não gostam de ler. Esse dado é preocupante, pois a Educação Ambiental valoriza os conhecimentos adquiridos.

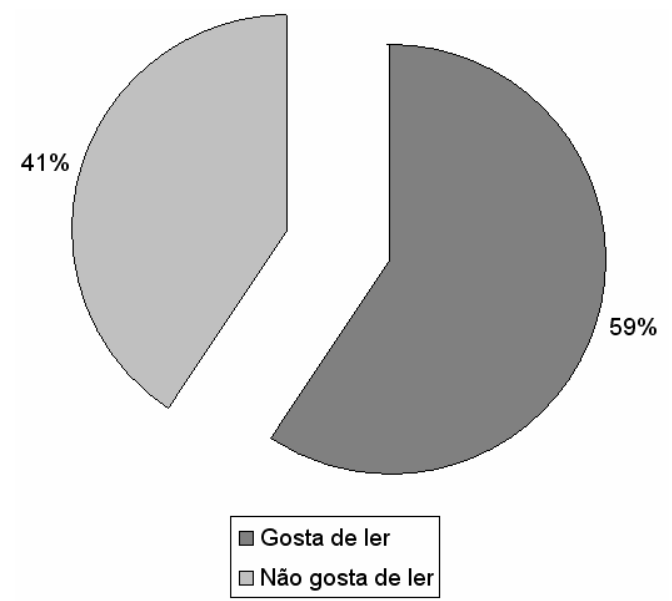

Figura 4 - Hábito de leitura dos entrevistados. 


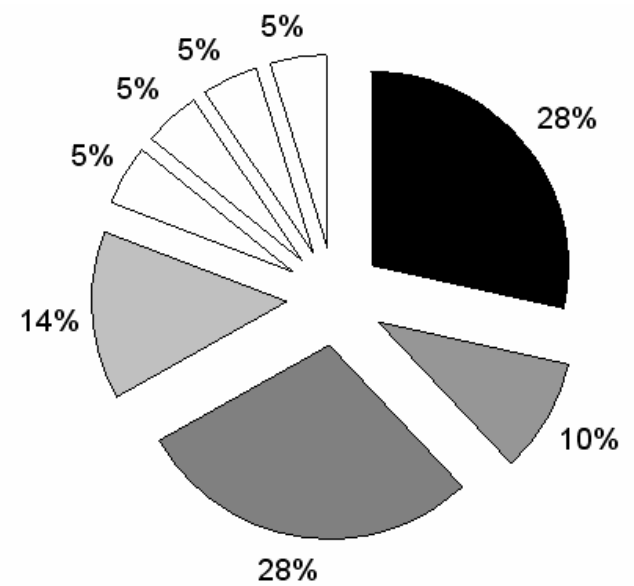

Assistem novelas, jornais e programas infantis $\square$ Assistem Novelas e programas infantis

$\square$ Assiste novelas e jornais

$\square$ Assistem novelas, jornais e filmes

$\square$ Assistem somente jornais

$\square$ Assistem somente novelas

$\square$ Assistem novelas e filmes

$\square$ Assistem novelas, jornais, programas infantis e filmes

Figura 5 - Programas de TV assistidos.

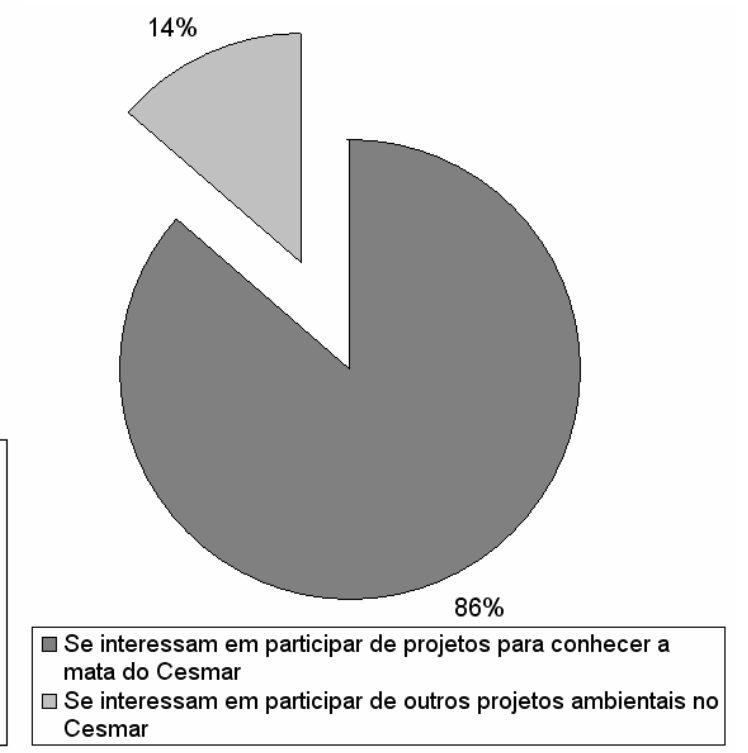

Figura 6 - Interesse em participar de projetos na mata do CESMAR

Já na figura 6, percebe-se que os entrevistados valorizam a instituição, $86 \%$ dos adolescentes têm interesse em participar de projetos envolvendo programas de Educação Ambiental.

VASCONCELOS (2004) sugere que a Educação Ambiental promova a cooperação e o diálogo entre indivíduos e instituições, com a finalidade de criar novos modos de vida.

Nas figuras 7, 8, 9 e 10 relacionadas às questões ambientais, percebe-se que os adolescentes valorizam a mata em questão. Dentre os entrevistados, $95 \%$ consideram a mata importante e demonstram a preocupação em conservá-la, pois há vínculo histórico, senso de pertença e respeito pelo ambiente.

Na figura 8 apenas $5 \%$ dos entrevistados disseram queimar o lixo, as queimadas são práticas recorrentes na comunidade. Pode-se dizer que é um elemento cultural da sociedade local. Elas queimam o lixo, pois acreditam que dessa forma, deixam o ambiente mais limpo.

Com relação ao aquecimento global, embora $86 \%$ dos entrevistados disseram saber alguma coisa, $11 \%$ ignoram o assunto. Isso revela a necessidade de um programa ambiental que trate das questões globais críticas. Na figura 10, nota-se que dentre os adolescentes, já existe uma consciência crítica construtiva, $63 \%$ dos entrevistados acreditam que uma das necessidades da 


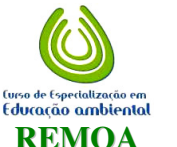

\section{Monografias Ambientais}

(Revista Eletrônica do PPGEAmb-CCR/UFSM) ISSN:

comunidade é o asfalto, 9\% acreditam que a comunidade necessita de relacionamentos, isso demonstra que já existe uma preocupação coletiva enfocando as relações humanas.

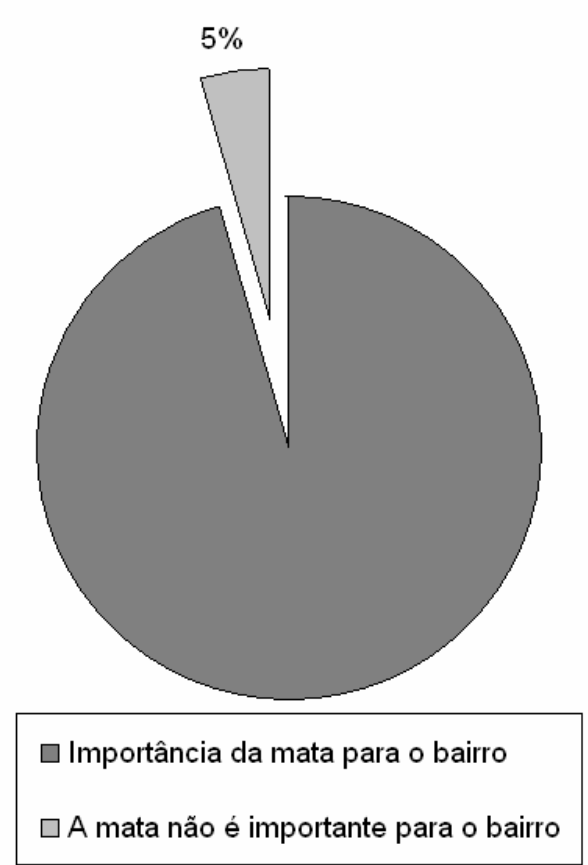

Figura 7 - Importância da mata

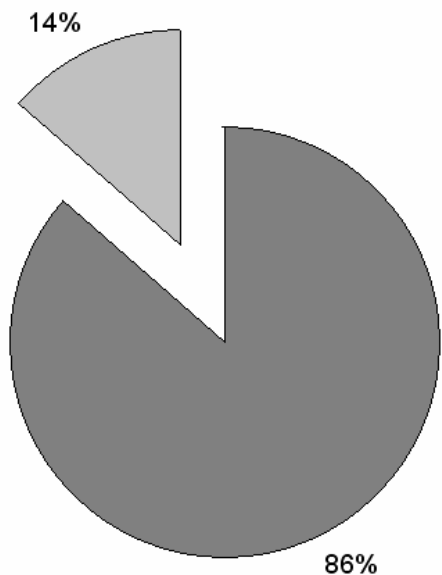

$\square$ Conhece sobre o aquecimento global

$\square$ Não sabe o que é o aquecimento global

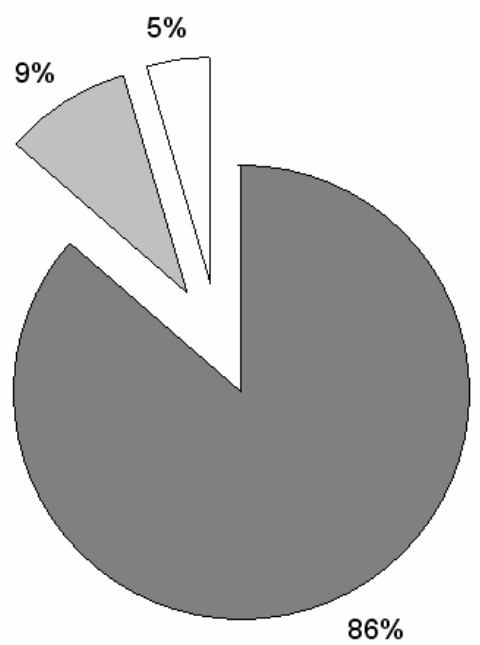

$\square$ Coleta pública de lixo $\square$ Reciclagem

$\square$ Queimadas

Figura 8 - Lixo Doméstico

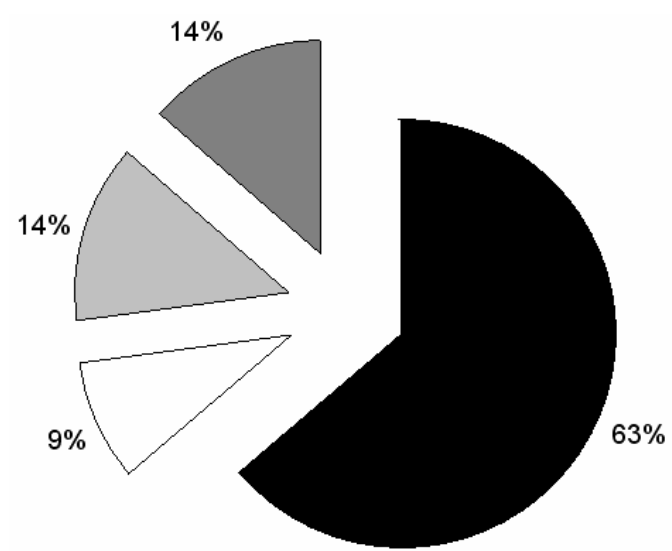

- A comunidade necessita de asfalto

$\square$ A comunidade necessita de relacionamentos

$\square$ A comunidade necessita de Higiene

$\square$ A comunidade necessita de segurança

Figura 9 - Sobre aquecimento Global.
Figura 10 - Necessidades da Comunidade 


\section{DISCUSSÃO E CONCLUSÕES}

MORIN (2002), diz que a educação do futuro deverá ser o ensino universal, centrado na condição humana. CAPRA (2002), citado por Vasconcellos (2006), reforça esse posicionamento ao afirmar que nas próximas décadas, a sobrevivência da humanidade vai depender da educação ecológica.

MEDINA e SANTOS (2001) enfatizam que não se trata apenas de ensinar sobre a natureza, mas educar para e com a natureza.

Uma dificuldade neste trabalho foi à ausência de dados de estudos científicos realizados na área, todos os dados apresentados neste estudo são de comunicação pessoal, fornecida por antigos moradores ou educandos do CESMAR.

Com base nos relatos históricos, verificou-se que alguns animais como cotias, pacas e tartarugas reduziram suas populações, bem como, muitas árvores foram derrubadas, isso é evidenciado pela degradação em decorrência da devastação ocorrida no entorno da mata localizada nas dependências do CESMAR.

Uma pequena população de macacos prego e alguns lagartos resistiram e ainda estão presentes na área. Como as populações humanas estão avançando cada vez mais sobre os limites deste ambiente, os macacos e humanos desenvolveram vínculos. Ao longo dos anos, as pessoas começaram a utilizar a área para o lazer e levavam comida para os animais. Isto acarretou aumento considerável do grupo de macacos, houve redução de alimento e este fato pode ter gerado estresse na população de macacos.

Os animais começaram a buscar alimento na casa dos Irmãos Maristas (localizada no espaço) e nas casas da vizinhança. Essa situação acarretou consideráveis problemas para a comunidade. Em 2004, os Irmãos Maristas realizaram uma pesquisa com ajuda da Polícia Florestal sendo retirados da área cerca de 30 macacos prego, os quais foram levados para uma chácara nas proximidades da cidade de Dourados.

Constatou-se que na comunidade, há um grupo considerável de pessoas que se preocupam com a mata e com os macacos prego, mas também há um pequeno grupo que gostaria que os macacos fossem retirados, pois acreditam que eles trazem doenças e incomodam.

O Centro Educacional e Social Marista aumentou seu espaço físico ampliando o número de atendimentos de adolescentes. Os educandos desejam andar na mata, ver os macacos prego, conhecer mais a realidade local e a história cultural. A comunidade aguarda a liberação do espaço físico para o lazer nos finais de semana e a solução para convivência saudável com os macacos prego.

Considerando os problemas apresentados na área estudada na comunidade e entorno, evidencia-se a necessidade de mudanças importantes no comportamento dos cidadãos em relação às questões ambientais, faz-se necessário o uso de instrumentos transformadores de conduta. Desta maneira, atividades envolvendo práticas de Educação Ambiental para crianças e adolescentes são de extrema importância na transformação da sociedade.

\section{REFERÊNCIAS BIBLIOGRÁFICAS}

ABEC - CESMAR Relatório Plano de Ação Dourados, MS, 2007. 


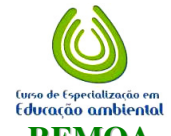

(Revista Eletrônica do PPGEAmb-CCR/UFSM) ISSN:

ALBERTI V. História oral a experiência do cpdoc. Rio de janeiro: fundação Getúlio Vargas; 1990.

C.D.B ( Convenção sobre diversidade biológica) 2005,0 Panorama da Biodiversidade 2. Disponível em www.biodov.org.org acesso em 02.11 .08

CAPRA, F. As Conexões Ocultas ciência para uma vida sustentável São Paulo 2002, 296p.

CARLINI-COTRIN, B., Potencialidades da técnica qualitativa grupo focal em investigações sobre abuso de substâncias. Revista de Saúde Pública, 1996. 30:285-293p

COMISSÃO INTERPROVINCIAL DE EDUCAÇÃO. Missão educativa marista: um projeto para o nosso tempo. Tradução de Manoel Alves, Ricardo Tescarolo. São Paulo: Simar, Secretaria Interprovincial Marista. 3. Ed. 2003.

CONSTITUIÇÃO DA REPÚBLICA DO BRASIL, 1988. Disponível em www.planalto.gov.br acesso em 13 de julho de 2007.

DIAS, Genebaldo Freire. Pegada ecológica e sustentabilidade humana São Paulo, Gaia, 2002.

GONÇALVES, Carlos Walter Porto. Os descaminhos do meio ambiente. São Paulo, 2 ed., Contexto 1990.

IBGE Cidades - Censo 2007 disponível em www.ibge.gov.br/cidadesat acesso em 20 de junho de 2008.

MEDINA, N. M. Santos E.C. Educação Ambiental uma metodologia participativa de formação, Rio de Janeiro Vozes 2001. 231p.

MINAYO, M. C. De S. O Desafio do Conhecimento: pesquisa qualitativa em saúde. Capítulo n.3 Fase de trabalho de campo. São Paulo-Rio de Janeiro, Hucitec-ABRASCO, 1996.105-134p.

Ministério do Meio ambiente - Inter-relações entre biodiversidade climáticas. Capítulo 4: Opções de mitigação e de adaptação a mudança climática: conexões com biodiversidade e impactos sobre a biodiversidade. 2 edição Brasília, 2007. 82-8p.

MORIN, Edgar Os sete saberes necessários à educação do futuro/ tradução de Catarina Eleonora F. da Silva e Jeanne Sawaya; revisão técnica de Edgard de Assis Carvalho.- Capítulo II Ensinar a Condição Humana São Paulo : Cortez; Brasília, DF ; UNESCO, 2002 .47-62 p.

Prefeitura de Dourados Perfil. Disponível em www.dourados.m.s.gov.br acesso 15 de agosto de 2008.

PRIMACK, Richard B.; Efraim Rodrigues. Biologia da Conservação - Londrina - PR. Editora Planta, 2007.

SATO Michèle, Educação Ambiental São Carlos, Rima 2004.

UNESCO/PNUMA. 1987. Estrategia internacional de acción en materia de educación y formación ambientales para el decenio de 1990. Moscou, UNESCO.

VASCONCELLOS, J.M.O. Educação e Interpretação Ambiental em Unidades de Conservação. Caderno de conservação ano 3 Curitiba Fundação O Boticário de Proteção à Natureza 2006.

VELOSO, H. P.; RANGEL FILHO; A L.R.; LIMA, J. C. A. Classificação da Vegetação Brasileira, adaptada a um sistema universal. Rio de Janeiro: IBGE, Departamento de Recursos Naturais e Estudos Ambientais, 1991.124 p. www.ambientebrasil.com.br Acesso em: 25 de julho de 2007. 